\title{
Negative Resistance Effect and Charge Transfer Mechanisms in the Ion Beam Deposited Diamond Like Carbon Superlattices
}

\author{
Andrius VASILIAUSKAS *, Šarūnas MEŠKINIS, Sigitas TAMULEVIČIUS \\ Institute of Materials Science of Kaunas University of Technology, Savanoriu 271, LT-50131 Kaunas, Lithuania \\ Received 25 June 2010; accepted 02 February 2011
}

\begin{abstract}
In the present study DLC:SiO $/ \mathrm{DLC} / \mathrm{DLC}: \mathrm{SiO}_{\mathrm{x}} / n \mathrm{Si}$ and $\mathrm{DLC}: \mathrm{SiO}_{\mathrm{x}} / \mathrm{DLC} / \mathrm{DLC}: \mathrm{SiO}_{\mathrm{x}} / p \mathrm{Si}$ structures were fabricated by ion beam deposition using a closed drift ion source. Current-voltage (I-V) characteristics of the multilayer samples were measured at room temperature. The main charge transfer mechanisms were considered. Unstable negative resistance effect was observed for some DLC:SiO of the diamond like carbon superlattices fabricated on $n \mathrm{Si}$ it was observed only during the first measurement. In the case

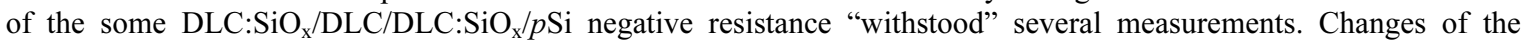
charge carrier mechanisms were observed along with the dissapear of the negative resistance peaks. It seems, that in such a case influence of the bulk related charge transfer mechanisms such as Poole-Frenkel emission increased, while the influence of the contact limited charge transfer mechanisms such as Schottky emission decreased. Observed results were be explained by current flow through the local microconducting channels and subsequent destruction of the localized current pathways as a result of the heating by flowing electric current.

Keywords: diamond like carbon, superlattice, electrical properties, negative resistance, charge transfer mechanisms.
\end{abstract}

\section{INTRODUCTION}

Diamond like carbon (DLC) films received significant attention due to their outstanding mechanical, electrical and optical properties [1]. Particularly, present and prospective electronic applications of DLC films include electrically active passivation of high power electronics devices [2], material for fabrication of the membranes in microelectromechanical systems (MEMS) [3], piezoresistive [4-6] and electrochemical sensors [7]. Recently fabrication of the diamond like carbon based resonant tunnel diodes (RTD) operating at microwave frequencies range was reported in $[8,9]$. Characteristic to the currentvoltage relationship of a tunneling diode is the presence of one or more negative differential resistance regions, which enables many unique applications. Diamond like carbon based resonant tunnel diode (RTD) could find a lot of the potential applications in large area electronics due to the room temperature deposition possibility. However, in $[8,9]$ DLC based RTD structures were grown using complex method of the pulsed laser deposition and negative resistance effect in these structures was observed only at liquid nitrogen temperature.

In the present research multilayer DLC films were deposited by closed drift ion source which is already used in industry due to the large area deposition possibility and easy of maintenance. Current-voltage dependences of these structures were investigated and negative resistance effect observed for some samples at room temperature was analyzed in terms of charge transfer mechanisms.

\section{EXPERIMENTAL}

Multilayer diamond like carbon films (DLC superlattices) were deposited on $\mathrm{n}$ type and $\mathrm{p}$ type monocrystalline silicon (100) substrates by closed drift ion

\footnotetext{
*Corresponding author. Tel.: +370-37-327605, fax.: +370-37-314423.

E-mail address: sarunas.meskinis@ktu.lt (A. Vasiliauskas)
}

source. Silicon substrates before diamond like carbon growth were cleaned by degreasing in dimethylformamide and acetone. "Conventional" diamond like carbon (DLC) layers were deposited using acetylene gas. $\mathrm{SiO}_{\mathrm{x}}$ containing diamond like carbon films (DLC:SiO ${ }_{x}$ ) were deposited using mixture of the hexamethyldisiloxane vapor and hydrogen gas. Deposition rate of the DLC and DLC:SiO established for thicker ( $200 \mathrm{~nm}$ thickness) films, was 400 $\mathrm{nm} / \mathrm{h}$ and $440 \mathrm{~nm} / \mathrm{h}$ respectively. Dielectric permittivity of the DLC and DLC:SiO $\mathrm{Sin}_{\mathrm{x}}$ monolayer films of $200 \mathrm{~nm}$ thickness deposited on n-type silicon substrates was $\sim 7$ and $\sim 3$ respectively. Optical bandgap of DLC and DLC:SiO monolayer films of $200 \mathrm{~nm}$ thickness was $\sim 1.2 \mathrm{eV}$ and $\sim 2.5 \mathrm{eV}$ respectively. More details on the deposition conditions and structure of the multilayer DLC films (DLC superlattices) can be found in Table 1. It can be seen, that all DLC superlatices consisted of the narrow bandgap ultra-thin DLC layer inserted between the two ultra-thin wide bandgap DLC: $\mathrm{SiO}_{\mathrm{x}}$ layers. This structure is typical for the resonant tunnel diode (RTD). Pulsed laser deposited diamond like carbon based RTD structure exhibiting negative resistance effect at liquid nitrogen temperature of the similar design was used in $[8,9]$.

After the DLC film synthesis, the samples were moved to the vacuum evaporation chamber as soon as possible. Top contacts were deposited onto the multilayer diamond like film via mask. The diameter of circular shaped top electrode was $500 \mu \mathrm{m}$. Afterwards bottom common electrodes were deposited onto the back surface of the silicon. Aluminum of $300 \mathrm{~nm}$ thickness was used as an electrode metal.

In present study Schottky emission [10, 11], FowlerNordheim tunneling, trap activated tunneling [12], space charge limited current $[10,11]$, Poole-Frenkel emission $[10,11]$ were considered as a possible charge transfer mechanisms. It should be mentioned, that in the case of the space charge limited current flow through the ideal defectfree dielectric $J \sim V^{2}$ current-voltage relationship will be 
Table 1. Deposition conditions and structure of the diamond like carbon superlattices.

\begin{tabular}{|c|c|c|c|c|c|c|c|c|c|c|}
\hline \multirow{2}{*}{$\begin{array}{c}\text { Sample } \\
\text { set name }\end{array}$} & \multirow{2}{*}{$\begin{array}{c}\text { Ion beam } \\
\text { energy } \\
(\mathrm{eV})\end{array}$} & \multicolumn{3}{|c|}{$\begin{array}{l}\text { Structure of diamond like carbon } \\
\text { superlattice }\end{array}$} & \multicolumn{3}{|c|}{ Deposition time (s) } & \multicolumn{3}{|c|}{ Thickness (nm)* } \\
\hline & & I layer & II layer & III layer & I layer & II layer & III layer & I layer & II layer & III layer \\
\hline S414 & 800 & DLC: $\mathrm{SiO}_{\mathrm{x}}$ & $\overline{D L C}$ & DLC: $\mathrm{SiO}_{\mathrm{x}}$ & 40 & 10 & 40 & 5 & 1 & 5 \\
\hline S424 & 800 & DLC: $\mathrm{SiO}_{\mathrm{x}}$ & DLC & DLC: $\mathrm{SiO}_{\mathrm{x}}$ & 40 & 20 & 40 & 5 & 2 & 5 \\
\hline S434 & 800 & DLC: $\mathrm{SiO}_{\mathrm{x}}$ & DLC & DLC: $\mathrm{SiO}_{\mathrm{x}}$ & 40 & 30 & 40 & 5 & 3 & 5 \\
\hline S444 & 800 & DLC: $\mathrm{SiO}_{\mathrm{x}}$ & DLC & DLC: $\mathrm{SiO}_{\mathrm{x}}$ & 40 & 40 & 40 & 5 & 4 & 5 \\
\hline S222 & 800 & DLC: $\mathrm{SiO}_{\mathrm{x}}$ & DLC & DLC: $\mathrm{SiO}_{\mathrm{x}}$ & 25 & 20 & 25 & 3 & 2 & 3 \\
\hline S989 & 800 & DLC: $: \mathrm{SiO}_{\mathrm{x}}$ & DLC & DLC: $\mathrm{SiO}_{\mathrm{x}}$ & 90 & 80 & 90 & 11 & 9 & 11 \\
\hline SL10 & 800 & DLC: $\mathrm{SiO}_{\mathrm{x}}$ & - & - & 80 & - & - & 10 & - & - \\
\hline SL120 & 800 & DLC: $\mathrm{SiO}_{\mathrm{x}}$ & - & - & 960 & - & - & 120 & - & - \\
\hline
\end{tabular}

* approximate thickness calculated by using deposition rate of the thicker films.

observed [13], while $J \sim V^{n}$ with $n>2$ dependence will be seen in the case of the space charge limited current with exponential traps distribution [14].

\section{EXPERIMENTAL RESULTS}

\subsection{I-V characteristics and charge transfer mechanisms of the diamond like carbon superlattices on n-type silicon}

For all the samples fabricated on $\mathrm{n}-\mathrm{Si}$, diode like current-voltage (I-V) characteristics were observed (Figs. 1, 2). Breakdown voltages were in $10 \mathrm{~V}-35 \mathrm{~V}$ range (Fig. 1). For all the samples step-like breakdown (multiple breakdown events) can be seen. It can be explained by electrical breakdown via local defects (breakdown spots) similarly to the ultrathin silicon dioxide breakdown case [15]. It can be seen as well, that reverse I-V characteristics of the multilayer film samples are more scattered in comparison with the $\mathrm{DLC}: \mathrm{SiO}_{\mathrm{x}} / n \mathrm{Si}$ heterostructures. It seems, that the breakdown voltage increases with thickness of both DLC: $\mathrm{SiO}_{\mathrm{x}}$ and DLC films in superlattice structure.

Leakage current of the almost all multilayer DLC/nSi heterostructures was lower than leakage current of the DLC: $\mathrm{SiO}_{\mathrm{x}} / n \mathrm{Si}$ heterojunction. However, for most S222 set samples and for some samples of other sets it was valid only at relatively low voltages due to the "soft" breakdown (Fig. 1, b).

In low current $\left(10^{-7} \mathrm{~A} \div 10^{-6} \mathrm{~A}\right)$ and voltages $(0 \mathrm{~V} \div 5 \mathrm{~V})$ range, some kind of the current step can be seen for the most samples investigated. The most clearly it can be seen for $\mathrm{DLC}: \mathrm{SiO}_{\mathrm{x}} / n \mathrm{Si}$ heterojunction. While in the case of some superlatice based samples of the S222 and S989 sets the step was absent.

Voltage of the turning point of the $\mathrm{DLC}: \mathrm{SiO}_{\mathrm{x}} / \mathrm{nSi}$ was $\sim 3 \mathrm{~V}$ when thickness of DLC: $\mathrm{SiO}_{\mathrm{x}}$ film was $10 \mathrm{~nm}$ and $\sim 15 \mathrm{~V}$ when thickness of DLC: $\mathrm{SiO}_{\mathrm{x}}$ film was $120 \mathrm{~nm}$. Current strength of the turning point of the DLC: $\mathrm{SiO}_{x} / \mathrm{nSi}$ was $\sim 0.45 \mu \mathrm{A}$ when thickness of $\mathrm{DLC} \mathrm{SiO}_{\mathrm{x}}$ film was $10 \mathrm{~nm}$ and it was $\sim 0.098 \mu \mathrm{A}$ when thickness of DLC:SiO film was $120 \mathrm{~nm}$. It means, that some bulk-related charge transport mechanism at least partially should be responsible for such a phenomena $[10,11,13,14]$. Turning point voltage for all the DLC superlattices and $n \mathrm{Si}$ heterojunction reverse characteristics was in $(4.8-6.6) \mathrm{V}$ range and turning point current strength was in $(0.1-0.36) \mu \mathrm{A}$ range. No clear relation between the position of the step turning point and structure of the DLC superlattices was observed.
The reverse $\mathrm{I}-\mathrm{V}$ characteristics of the $\mathrm{DLC}: \mathrm{SiO}_{\mathrm{x}} / \mathrm{nSi}$ heterostructures were stable versus time and cycles of measurements. While for the multilayer DLC and $\mathrm{n}-\mathrm{Si}$ heterostructures in most cases some kind of degradation of the I-V characteristics was observed with number of measurements (Fig. 1, d).

Both contact-limited and bulk-limited charge transfer mechanisms such as Schottky emission, Fowler-Nordheim tunneling, trap activated tunneling as well as space charge limited currents (SCLC) and Poole-Frenkel emission were considered to reveal reasons of the peculiarities and stability of the I-V characteristics mentioned above.

Linear or quasilinear dependences were observed in the case of the Schottky, Poole-Frenkel and double logarithmic plots of the reverse I-V characteristics of the samples (Fig. 3). Additional analysis of these plots was performed. Effective dielectric permittivity was calculated from the slope of the linear parts of the Schottky and Poole-Frenkel plots. While in the case of the double logarithmic plot more precise analysis of the $J \sim V^{n}$ dependence has been made. It can be seen in Table 2, that in the low voltages range reasonable effective dielectric permittivity values was observed for Schottky plot, and effective dielectric permittivity values calculated from the Poole-Frenkel plot were higher (yet $\varepsilon_{P F}$ of the single layer DLC: $\mathrm{SiO}_{\mathrm{x}} / n \mathrm{Si}$ heterostructure was close to the $\varepsilon_{C V}$ of DLC and DLC: $\mathrm{SiO}_{\mathrm{x}}$ films). Slope of the double logarithmic plot at low voltages range was too high for space charge limited current case $\left(J \sim V^{n}\right.$ with $\left.n>4.5\right)$. At higher voltages (higher than voltage of the turning point of the I-V step) large or even negative values of the $\varepsilon_{S c h}$ and $\varepsilon_{P F}$ were observed. On the other hand $J \sim V^{n}$ dependence with $n$ close to 1 can be seen in double logarithmic plot (quasilinear dependence). It means, that at low voltage (or low electric field strength range) Schottky emission is the main charge transport mechanism in multilayer DLC and $n \mathrm{Si}$ structures, while for the single layer $\mathrm{DLC}: \mathrm{SiO}_{\mathrm{x}} / n \mathrm{Si}$ heterostructure Poole-Frenkel emission plays important role along with the Schottky emission. At higher reverse voltages charge transport can be described as a superposition of the space charge limited current $\left(J \sim V^{2}\right.$ for ideal dielectric) and generation current $\left(J \sim V^{0.5}\right)$.

Instability of the reverse I-V characteristics of the samples presented in Fig. 1, d, was considered in terms of the charge transport mechanisms as well. There were revealed, that in the case of the subsequent measurements (second, third, etc.) quasilinear regions of the double logarithmic plot can be described by $J \sim V^{n}$ function with 

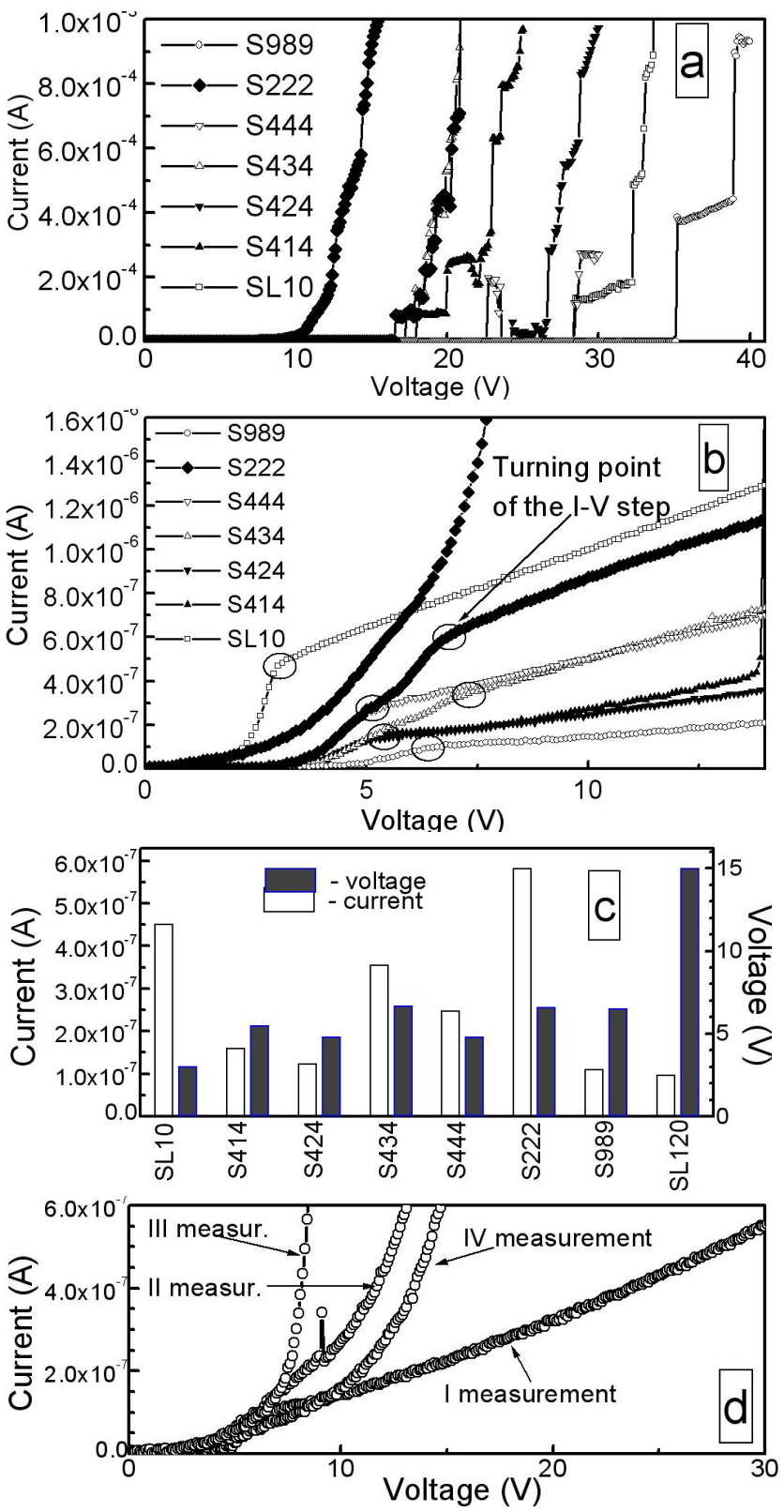

Fig. 1. Typical reverse current-voltage (I-V) characteristics of DLC: $\mathrm{SiO}_{\mathrm{x}} / \mathrm{DLC} / \mathrm{DLC}: \mathrm{SiO}_{\mathrm{x}} / n \mathrm{Si}$ samples: overall view (a), low current range (b); position of the turning point (c) and typical measurement induced changes of the reverse I-V characteristic (d)

$n>3$. Analysis of the Schottky, Poole-Frenkel, FowlerNordheim and trap assisted tunneling plots was performed as well. There were revealed, that in the lower voltages range charge transport can be described as a superposition of the Schottky and Poole-Frenkel emission. On the other hand, exponentially distributed trap space charge limited current and, probably, Fowler-Nordheim emission can be considered at the higher voltage range. It seems, that electric current flow through the multilayer DLC film (DLC superlattice) results in formation of some additional defects. Such an effect was not observed for the single DLC: $\mathrm{SiO}_{\mathrm{x}} / n \mathrm{Si}$ heterostructure. Therefore, formation of the traps as a result of the damage of the "conventional" DLC interlayer in diamond like carbon superlattice can be supposed.

Typical forward I-V characteristics of the samples fabricated on n-type $\mathrm{Si}$ are presented in Fig. 2. In most cases some instability of the forward I-V characteristics was observed. In the case of the $\mathrm{DLC}: \mathrm{SiO}_{\mathrm{x}} / n \mathrm{Si}$ heterostructure (film thickness $10 \mathrm{~nm}$ ) I type forward I-V characteristics was observed - during the second measurement forward voltage decreased and no additional changes of $\mathrm{I}-\mathrm{V}$ characteristic was observed during the next measurements. In the case of the multilayer DLC heterostructures with $n \mathrm{Si}$ for some samples some kind of the negative resistance effect was observed. It seems, that negative resistance phenomenon was more often observed in the case of the samples with thicker intermediate DLC interlayer ( $\geq 4 \mathrm{~nm})$ - S444 and, especially, S989. However, negative resistance phenomenon was unstable - in all cases it was observed only during the first measurement.

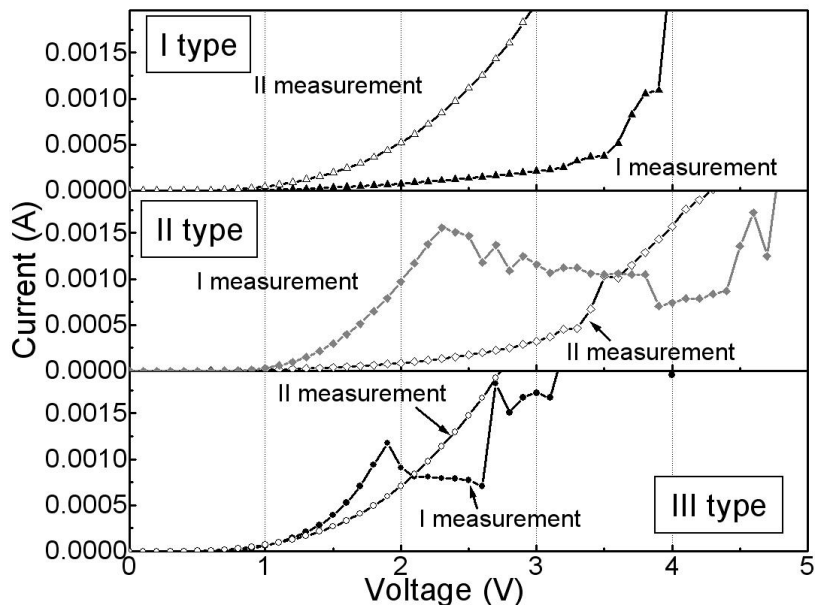

Fig. 2. Typical forward I-V characteristics of current-voltage (I-V) characteristics of DLC: $\mathrm{SiO}_{\mathrm{x}} / \mathrm{DLC} / \mathrm{DLC}: \mathrm{SiO}_{\mathrm{x}} / n \mathrm{Si}$ samples (presented I type I-V characteristic was measured for the sample from S444 set, II type - for the sample from S424 set and III type - for the sample from S414 set)

Study of the charge transport mechanisms was performed by using analysis of the I-V characteristics. Linear or quasilinear ranges were observed in Schottky, Poole-Frenkel, double logarithmic, Fowler-Nordheim tunneling and trap activated tunneling plots (Figs. 4, 5). The results of the analysis are presented in Table 3.

Analysis of I type (S444) I-V characteristics revealed, that in the low voltage range the main charge transfer mechanism is Schottky emission, at higher voltages Schottky emission and space charge limited current with exponential trap distribution and at the highest voltages possibly Fowler-Nordheim and/or trap activated tunneling. In the case of the second measurement at low voltages Schottky emission and Poole-Frenkel emission prevailed, at higher voltages - space charge limited current with exponential trap distribution as well as possibly FowlerNordheim and/or trap activated tunneling. Analysis of II type (S424) I-V characteristics revealed, that in the case of the first measurement in low voltages range (before negative resistance region) the main charge transfer mechanisms were Schottky emission and Poole-Frenkel emission as well as possibly Fowler-Nordheim and/or trap activated tunneling. In the case of the second measurementit was Poole-Frenkel emission, Schottky emission and space charge limited current with SCLC prevailing at higher voltages and Schottky emission as well as Poole Frenkel emission at lower voltages. Analysis of III type 
Table 2. $\varepsilon_{S c h}, \varepsilon_{P F}$ and $n$ values of the reverse I-V characteristics of I-V characteristics of DLC:SiO $/ \mathrm{DLC}_{\mathrm{DLC}}: \mathrm{SiO}_{\mathrm{x}} / n \mathrm{Si}$ samples

\begin{tabular}{|c|c|c|c|c|c|c|}
\hline Sample's set & $\begin{array}{l}\text { Electric field range } \\
(\mathrm{kV} / \mathrm{cm})\end{array}$ & $\varepsilon_{S c h}$ & $\begin{array}{l}\text { Electric field range } \\
\qquad(\mathrm{kV} / \mathrm{cm})\end{array}$ & $\varepsilon_{P F}$ & $\begin{array}{l}\text { Electric field range } \\
(\mathrm{kV} / \mathrm{cm})\end{array}$ & $n$ in $J \sim V^{n}$ \\
\hline \multirow{2}{*}{ SL10 } & $1400-3000$ & 3.6 & $1400-3000$ & 5.8 & $1400-3000$ & 5.68 \\
\hline & $3000-25000$ & 937 & $3000-25000$ & $<0$ & $3000-25000$ & 1.25 \\
\hline \multirow{4}{*}{ S434 } & $3000-4000$ & 5.6 & $3000-4000$ & 46.7 & $3000-4000$ & 5.60 \\
\hline & $4000-5000$ & 37.5 & $4000-5000$ & 713 & $4000-6000$ & 2.00 \\
\hline & $5000-6500$ & 178.4 & $5000-13000$ & 86000 & $6000-13000$ & 1.14 \\
\hline & $6500-13000$ & 440.6 & & & & \\
\hline \multirow{2}{*}{ S444 } & $2500-3600$ & 5.4 & $2500-3600$ & 33.2 & $2500-3600$ & 5.95 \\
\hline & $3600-15500$ & 440 & $3600-15500$ & $<0$ & $3600-15500$ & 0.97 \\
\hline \multirow{3}{*}{ S989 } & $1500-2000$ & 4.2 & $1500-2200$ & 27.5 & $1500-2200$ & 4.67 \\
\hline & $2000-10000$ & 215 & $2200-3000$ & $<0$ & $2200-3000$ & 0.64 \\
\hline & & & $3000-10000$ & 21000 & $3000-10000$ & 1.24 \\
\hline
\end{tabular}
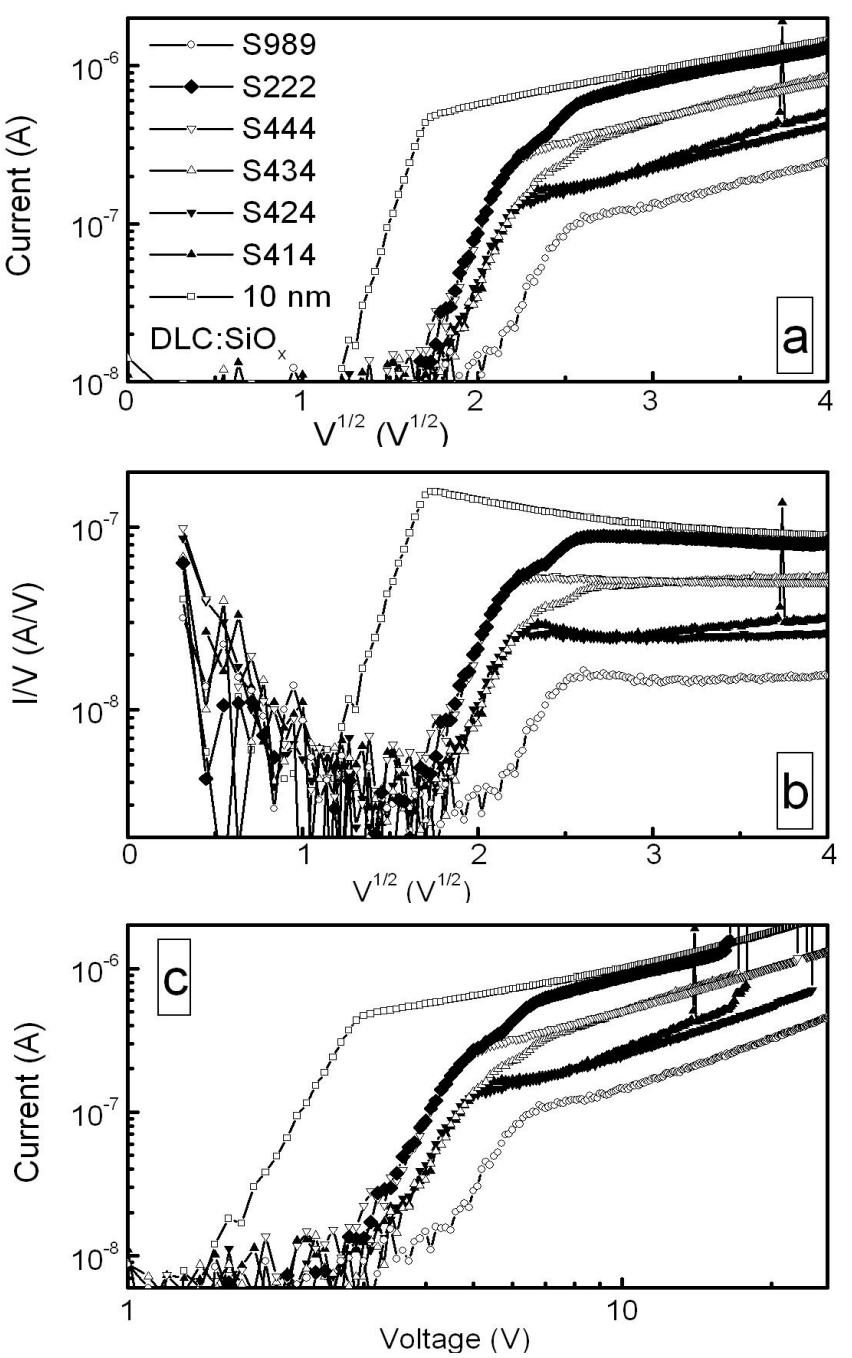

Fig. 3. Schottky (a), Poole-Frenkel and double logarithmic plots of current-voltage (I-V) characteristics of DLC: $\mathrm{SiO}_{\mathrm{x}} / \mathrm{DLC} / \mathrm{DLC}: \mathrm{SiO}_{\mathrm{x}} / n \mathrm{Si}$ samples. (I type I-V characteristic - sample from S444 set, II type - sample from S424 set and III type-sample from S414 set)

(S414) I-V characteristics revealed, that in the case of the first measurement the main charge transfer mechanisms are Schottky emission and space charge limited current as well as possibly recombination current in low voltages range, Poole-Frenkel emission in middle voltages range and
Schottky emission as well as possibly Fowler-Nordheim and/or trap activated tunneling in highest voltages range. It seems, that the influence of the potential barriers in DLC: $\mathrm{SiO}_{\mathrm{x}} / \mathrm{DLC} / \mathrm{DLC}: \mathrm{SiO}_{\mathrm{x}}$ superlattice should be taken into account $[10,11]$. In the case of the second measurement the main charge transfer mechanisms were Poole-Frenkel emission in lower voltages range and space charge limited current with exponential trap distribution as well as possibly Fowler-Nordheim and/or trap activated tunneling in higher voltages range. It seems, that in the case of the samples with negative resistance range in I-V characteristics, current induced damages resulted in both disappearance of the negative resistance phenomena and contact limited charge transport mechanisms in the samples. While for the samples with no negative resistance phenomena observed, current induced damages resulted in flow of the mixed contact and bulk limited current at lower voltages instead of the contact limited current.

Data on peak current and voltage of the current peak are presented in Fig. 6 . The current of the negative resistance peak in all cases was in $(0.6-0.24) \mathrm{mA}$ range, while voltage of the peak was in $2 \mathrm{~V}-4 \mathrm{~V}$ range samples of the

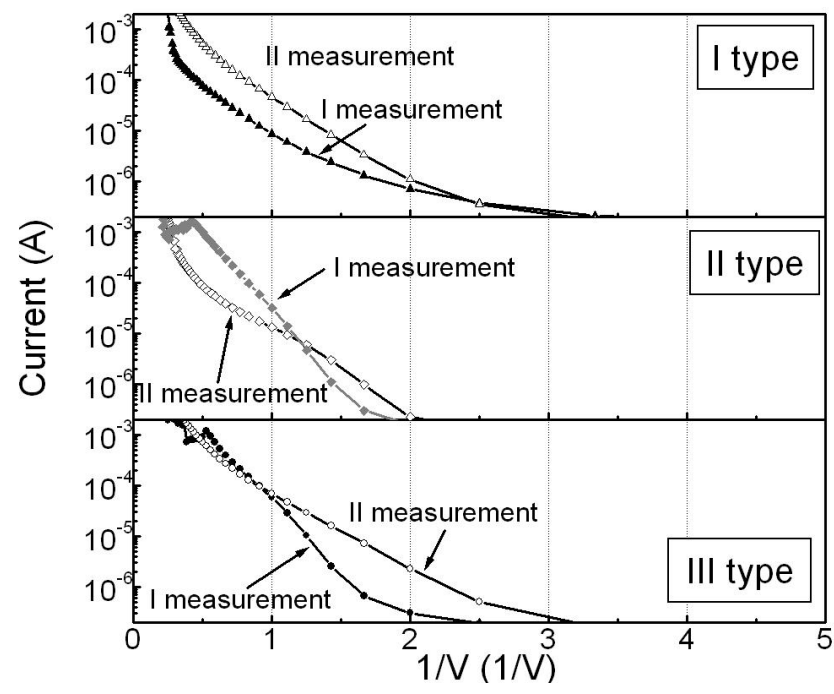

Fig. 4. Trap activated tunneling plot of the forward I-V characteristics of DLC: $\mathrm{SiO}_{\mathrm{x}} / \mathrm{DLC} / \mathrm{DLC}: \mathrm{SiO}_{\mathrm{x}} / n \mathrm{Si}$ samples. (presented I type I-V characteristic was measured for the sample from S444 set, II type - for the sample from S424 set and III type - for sample from S414 set) 
Table 3. $\varepsilon_{S c h}, \varepsilon_{P F}$ and $n$ values of the forward I-V characteristics of DLC:SiO $/$ DLC/DLC:SiO $/ n$ Si samples

\begin{tabular}{|c|c|c|c|c|c|c|c|}
\hline $\begin{array}{l}\text { Sample's } \\
\text { set }\end{array}$ & $\begin{array}{l}\text { Meas. } \\
\text { No }\end{array}$ & $\begin{array}{l}\text { Electric field range } \\
(\mathrm{kV} / \mathrm{cm})\end{array}$ & $\varepsilon_{S c h}$ & $\begin{array}{l}\text { Electric field range } \\
\qquad(\mathrm{kV} / \mathrm{cm})\end{array}$ & $\varepsilon_{P F}$ & $\begin{array}{l}\text { Electric field range } \\
(\mathrm{kV} / \mathrm{cm})\end{array}$ & $\begin{array}{c}n \text { in } J \sim V^{n} \\
\text { plot }\end{array}$ \\
\hline \multirow{7}{*}{ S414 } & \multirow{4}{*}{1} & $100-350$ & 59.8 & $100-350$ & $<0$ & $100-300$ & 0.23 \\
\hline & & $350-550$ & 2.61 & $350-550$ & 23.21 & $300-450$ & 1.58 \\
\hline & & $550-900$ & 0.48 & $550-800$ & 2.07 & $450-800$ & 7.98 \\
\hline & & $1700-2400$ & 3.21 & $800-1700$ & 0.19 & $800-1700$ & 4.8 \\
\hline & \multirow{3}{*}{2} & $100-300$ & 74.7 & $100-300$ & $<0$ & $100-300$ & 0.33 \\
\hline & & $300-650$ & 0.74 & $300-700$ & 4.96 & $300-650$ & 5.56 \\
\hline & & $650-2800$ & 6.88 & $700-1200$ & 30.74 & $650-2800$ & 3.41 \\
\hline \multirow{11}{*}{ S424 } & \multirow{6}{*}{1} & $70-350$ & 178.41 & $70-300$ & $<0$ & $70-350$ & 0.21 \\
\hline & & $350-800$ & 0.44 & $300-400$ & 51.37 & $350-700$ & 8.1 \\
\hline & & $800-1600$ & 3.21 & $400-600$ & 1.52 & $700-1700$ & 4.44 \\
\hline & & $1600-3000$ & $<0$ & $600-1500$ & 14.56 & $1700-2700$ & $<0$ \\
\hline & & $3000-3500$ & 3.06 & $1500-3000$ & $<0$ & $2700-3500$ & 6.15 \\
\hline & & & & $3000-3500$ & 16.2 & & \\
\hline & \multirow{5}{*}{2} & $70-300$ & 599.67 & $70-300$ & $<0$ & $70-300$ & 0.11 \\
\hline & & $300-550$ & 0.6 & $300-550$ & 3.5 & $300-550$ & 5.95 \\
\hline & & $550-3500$ & 7.14 & $550-2400$ & 70.62 & $550-2300$ & 2.97 \\
\hline & & & & $2400-3500$ & 178.41 & $2300-2500$ & 9.57 \\
\hline & & & & & & $2500-3500$ & 2.88 \\
\hline \multirow{8}{*}{ S444 } & \multirow{4}{*}{1} & $100-300$ & 48.95 & $100-350$ & $<0$ & $100-300$ & 0.42 \\
\hline & & $300-1000$ & 2.85 & $350-1300$ & 24.81 & $300-1100$ & 3.29 \\
\hline & & $1000-1500$ & 7.14 & $1300-3000$ & 163.24 & $1100-3000$ & 2.72 \\
\hline & & $1500-3000$ & 18.67 & & & $3000-3600$ & 10.12 \\
\hline & \multirow{4}{*}{2} & $100-300$ & 84.33 & $100-350$ & $<0$ & $100-300$ & 0.3 \\
\hline & & $300-900$ & 1.15 & $350-700$ & 5.27 & $300-800$ & 4.93 \\
\hline & & $900-3000$ & 8.3 & $700-1300$ & 26.57 & $800-3000$ & 3.44 \\
\hline & & & & $1300-3000$ & 79.26 & & \\
\hline
\end{tabular}

sets S414, S424, S444, S222 and in 3.3 V-7.2 V range for samples of the set S989. It seems, that voltage of the current peak shifted to the higher voltages with increase of the thickness of the DLC: $\mathrm{SiO}_{\mathrm{x}} / \mathrm{DLC} / \mathrm{DLC}: \mathrm{SiO}_{\mathrm{x}}$ superlattice layers. Peak current decreased with increase of the peak voltage in the case of the samples of the sets S414, S424, S444, S222. While in the case of the samples of the set S989 there is no pronounced tendency.

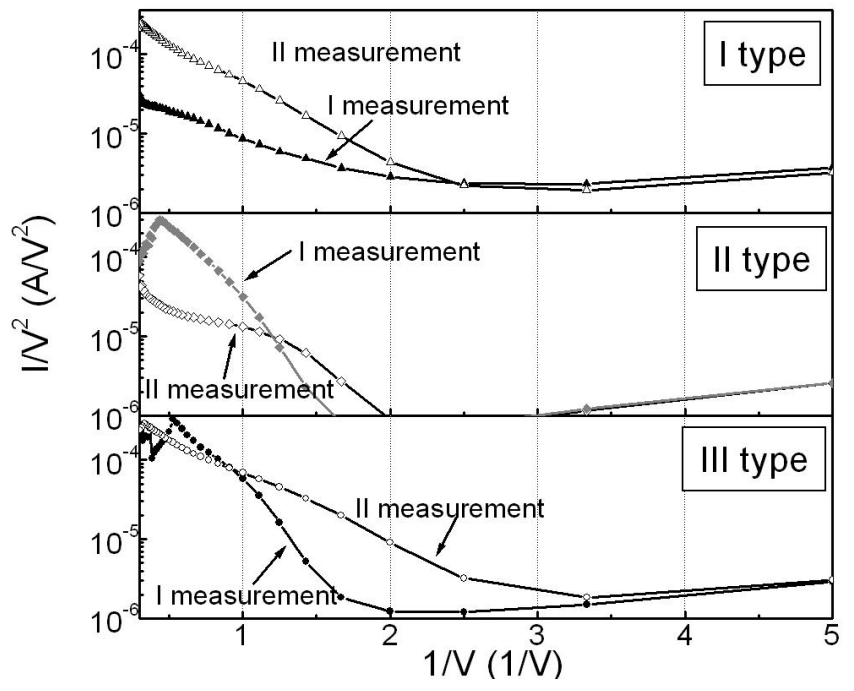

Fig. 5. Fowler-Nordheim tunneling plot of the forward $I-V$ characteristics of DLC:SiO $/ \mathrm{DLC} / \mathrm{DLC}: \mathrm{SiO}_{\mathrm{x}} / n \mathrm{Si}$ samples (presented I type I-V characteristic was measured for the sample from S444 set, II type - for the sample from S424 set and III type - for sample from S414 set)

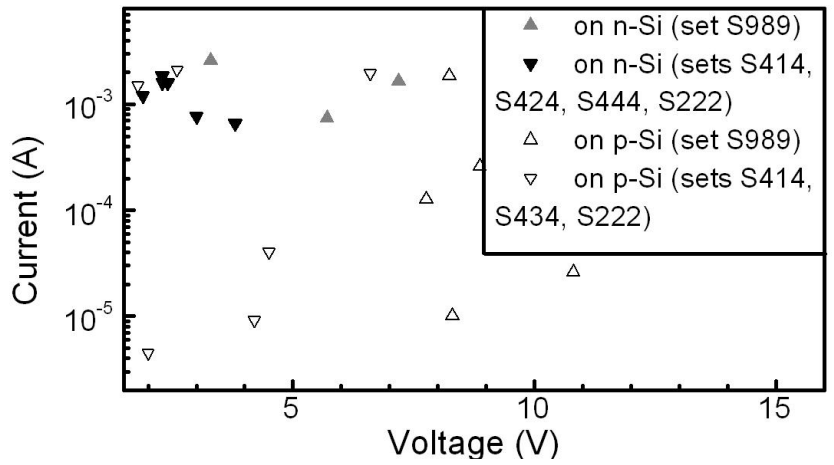

Fig. 6. Negative resistance effect data: peak current strength and voltage of the current peak

\subsection{I-V characteristics and charge transfer mechanisms of the diamond like carbon superlattices on p-type silicon}

In the case of the DLC:SiO$/ \mathrm{DLC} / \mathrm{DLC}: \mathrm{SiO}_{\mathrm{x}}$ superlattices fabricated on p-type silicon symmetric or quasi-symmetric I-V characteristics were observed. I-V characteristics of the part of the samples were linear. In other cases non-linear I-V characteristics were observed with turn-on voltage from several volts up to $20 \mathrm{~V}$. For the most samples electric current induced changes of the I-V characteristics - decreased the turn-on voltage or even induced transition to the ohmic conductivity (Fig. 7).

For some DLC:SiO $/$ DLC/DLC:SiO ${ }_{x}$ superlattices fabricated on p-type silicon the negative resistance effect was observed (Fig. 7). That effect was more pronounced 
Table 4. $\varepsilon_{S c h}, \varepsilon_{P F}$ and $n$ values of the forward I-V characteristics of DLC:SiO $/ \mathrm{DLC} / \mathrm{DLC}: \mathrm{SiO}_{\mathrm{x}} / p \mathrm{Si}$ samples

\begin{tabular}{|c|c|c|c|c|c|c|c|}
\hline Sample & $\begin{array}{l}\text { Meas. } \\
\text { No }\end{array}$ & $\begin{array}{l}\text { Electric field range } \\
(\mathrm{kV} / \mathrm{cm})\end{array}$ & $\varepsilon_{S c h}$ & $\begin{array}{l}\text { Electric field range } \\
(\mathrm{kV} / \mathrm{cm})\end{array}$ & $\varepsilon_{P F}$ & $\begin{array}{c}\text { Electric field } \\
\text { range }(\mathrm{kV} / \mathrm{cm})\end{array}$ & $\begin{array}{l}n \text { in } J \sim V^{n} \\
\text { plot }\end{array}$ \\
\hline \multirow{3}{*}{ S414 } & \multirow{3}{*}{1} & $650-800$ & 0.35 & $1100-1800$ & 118.45 & $650-800$ & 10.6 \\
\hline & & $800-1400$ & 3.84 & $1800-2300$ & $<0$ & $800-1800$ & 3.5 \\
\hline & & $1400-1800$ & 7.98 & $2300-2700$ & 48.95 & $650-800$ & 10.6 \\
\hline \multirow{6}{*}{ S434 } & \multirow{3}{*}{1} & $1100-1800$ & 11.68 & $1100-1800$ & 118.45 & $1100-1800$ & 2.6 \\
\hline & & $1800-2300$ & $<0$ & $1800-2300$ & $<0$ & $1800-2300$ & -7.3 \\
\hline & & $2300-2700$ & 7.14 & $2300-2700$ & 48.95 & $2300-2700$ & 15.9 \\
\hline & \multirow{3}{*}{2} & $80-300$ & 2 & $80-300$ & 29.61 & $80-900$ & 1.7 \\
\hline & & $300-700$ & 10.2 & $300-1100$ & 1066 & & \\
\hline & & $700-1100$ & 66.63 & & & & \\
\hline \multirow{9}{*}{$\begin{array}{l}\text { S989 } \\
\text { (III type } \\
\text { I-V) }\end{array}$} & \multirow{4}{*}{1} & $2300-2400$ & 0.03 & $2300-2400$ & 0.12 & $2300-2400$ & 66.4 \\
\hline & & $2500-3000$ & 66000 & $2500-3000$ & $<0$ & $2500-3000$ & 0.06 \\
\hline & & $3200-3500$ & 0.22 & $3200-3500$ & 0.94 & $3200-3500$ & 28.7 \\
\hline & & $3500-4000$ & 1.5 & $3500-4000$ & 7.27 & $3500-4000$ & 11.6 \\
\hline & \multirow{5}{*}{2} & $4200-6200$ & 2.2 & $4200-6200$ & 10.66 & $4200-6200$ & 11.3 \\
\hline & & $1700-1900$ & 0.27 & $1700-1900$ & 1.18 & $1700-1900$ & 19 \\
\hline & & $1900-2500$ & 3.06 & $1900-2500$ & 17.13 & $1900-2500$ & 6.2 \\
\hline & & $2500-5100$ & 5.44 & $2500-5100$ & 31.94 & $2500-5100$ & 5.9 \\
\hline & & $5200-6200$ & 2.44 & $5200-6200$ & 11.95 & $5200-6200$ & 11.2 \\
\hline \multirow{10}{*}{$\begin{array}{l}\text { S989 } \\
\text { (IV type } \\
\text { I-V) }\end{array}$} & & $2200-2400$ & 0.03 & $2200-2400$ & 0.14 & $2200-2400$ & 60.7 \\
\hline & & $2400-3900$ & 3.84 & $2400-3900$ & 21.76 & $2400-3900$ & 6.5 \\
\hline & & $3900-6100$ & 2 & $3900-6100$ & 9.57 & $3900-6100$ & 11.5 \\
\hline & & $1700-1900$ & 0.05 & $1700-1900$ & 0.19 & $1700-1900$ & 46.5 \\
\hline & & $1900-2800$ & 1162 & $1900-2800$ & $<0$ & $1900-2800$ & 0.31 \\
\hline & & $2800-3000$ & 1.55 & $2800-3000$ & 7.69 & $2800-3000$ & 10 \\
\hline & & $3100-6500$ & 2.85 & $3100-6500$ & 14.19 & $3100-6500$ & 9.3 \\
\hline & & $1800-1900$ & 0.13 & $1800-1900$ & 0.57 & $1800-1900$ & 27.6 \\
\hline & & $1900-2400$ & 1.47 & $1900-2400$ & 7.54 & $1900-2400$ & 8.87 \\
\hline & & $2400-6500$ & 4.53 & $2400-6500$ & 24.8 & $2400-6500$ & 6.96 \\
\hline
\end{tabular}

than in the case of the samples fabricated on $n$-Si: peak current was substantially higher than valley current for DLC: $\mathrm{SiO}_{\mathrm{x}} / \mathrm{DLC} / \mathrm{DLC}: \mathrm{SiO}_{\mathrm{x}}$ superlattices fabricated on $p$ type silicon (see Fig. 2). In the case of the DLC: $\mathrm{SiO}_{\mathrm{x}} / \mathrm{DLC} / \mathrm{DLC}: \mathrm{SiO}_{\mathrm{x}}$ superlattices fabricated on p-type silicon for some samples negative resistance effect remained after the first measurement. However, in such a case peak current decreased and, sometimes, shift of the current peak voltage was observed.

In the case of the I type sample possible charge transfer mechanisms were analyzed in the voltage range below the current peak voltage (Fig. 7, a, Table 4). There were revealed, that in this case Schottky emission as well as space charge limited current with exponential traps distribution seems to be the main charge transfer mechanisms. However, Fowler-Nordheim and trap activated tunneling mechanisms should be considered as well. No negative resistance effect was observed during the subsequent measurements. I-V characteristics measured during the subsequent measurements were noisy, therefore charge transfer mechanisms analysis was complicated.

In the case of the sample with II type I-V characteristic the main charge transfer mechanism in quasilinear I-V range below the current peak voltage was FowlerNordheim tunneling and space charge limited current with the exponential trap distribution $(n=3.27)$ at the lower voltages and space charge limited current $(n=1.9)$ at the higher voltages range (Table 4). Trap assisted current possibly can be considered as well. It seems, that the sample was irreversibly electrically damaged during the first measurement and subsequently substantially increased current and quasilinear $I$ vs $V$ dependence was observed (Fig. 7, b).

Analysis of the III type I-V characteristics revealed linear parts in Schottky emission, Poole-Frenkel, double logarithmic, trap activated tunneling and Fowler-Nordheim plots. However, in the case of the Schottky and Poole Frenkel plots unrealistically high values of the dielectric permittivity were achieved (current increase with voltage was too slow) (Table 4). While in the case of the double logarithmic plot current increase with voltage was relatively sudden $\left(n>3.8\right.$ in $J \sim V^{n}$ plot) (Table 4$)$. It seems, that in this case the main charge transfer mechanisms are Fowler-Nordheim emission and/or trap activated tunneling In the case of the IV type I-V characteristics the main charge transfer mechanisms seems to be Fowler-Nordheim emission and/or trap activated tunneling (Fig. 8).

\section{DISCUSSION}

In summary $\mathrm{I}-\mathrm{V}$ characteristics of the multilayer DLC: $\mathrm{SiO}_{\mathrm{x}} / \mathrm{DLC} / \mathrm{DLC}: \mathrm{SiO}_{\mathrm{x}} / n \mathrm{Si}$ and DLC:SiO $\mathrm{S}_{\mathrm{x}} / \mathrm{DLC} /$ $/ \mathrm{DLC}: \mathrm{SiO}_{\mathrm{x}} / p \mathrm{Si}$ samples were investigated. Diode-like I-V characteristics were observed for the $\mathrm{DLC}: \mathrm{SiO}_{\mathrm{x}} / \mathrm{DLC} /$ $/ \mathrm{DLC}: \mathrm{SiO}_{\mathrm{x}} / n \mathrm{Si}$ structures. The leakage current of the almost all diamond like carbon superlatice and $n \mathrm{Si}$ heterostructures was lower than the leakage current of the single layer DLC: $\mathrm{SiO}_{\mathrm{x}} / n \mathrm{Si}$ heterojunction. Inthe case of the reverse $\mathrm{I}-\mathrm{V}$ characteristics of single layer $\mathrm{DLC}: \mathrm{SiO}_{\mathrm{x}} / n \mathrm{Si}$ 

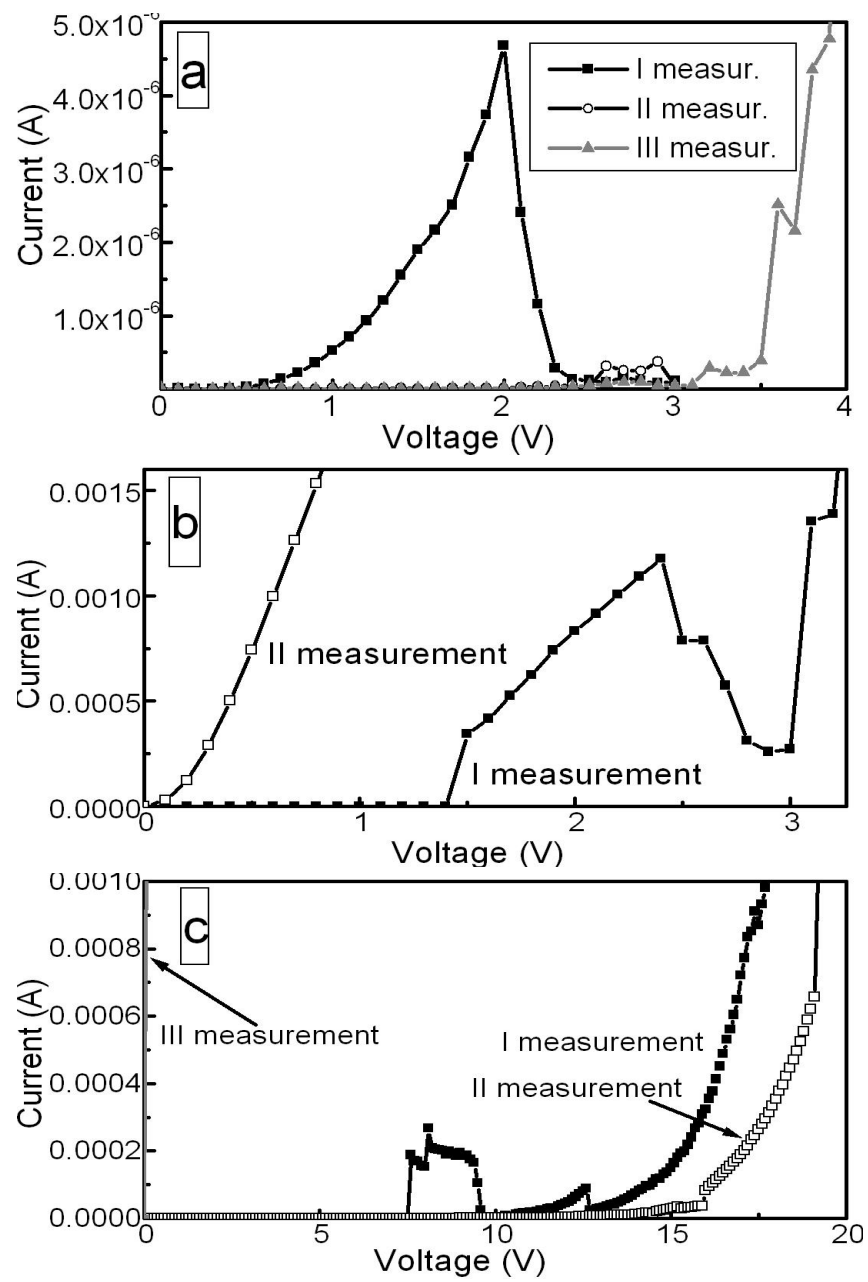

Fig. 7. Typical I-V characteristics of DLC: $\mathrm{SiO}_{\mathrm{x}} / \mathrm{DLC} / \mathrm{DLC}: \mathrm{SiO}_{\mathrm{x}}$ superlattices fabricated on p-type silicon: I type (sample's set S414) (a), II type (sample's set S434) (b), III type (sample's set S989)
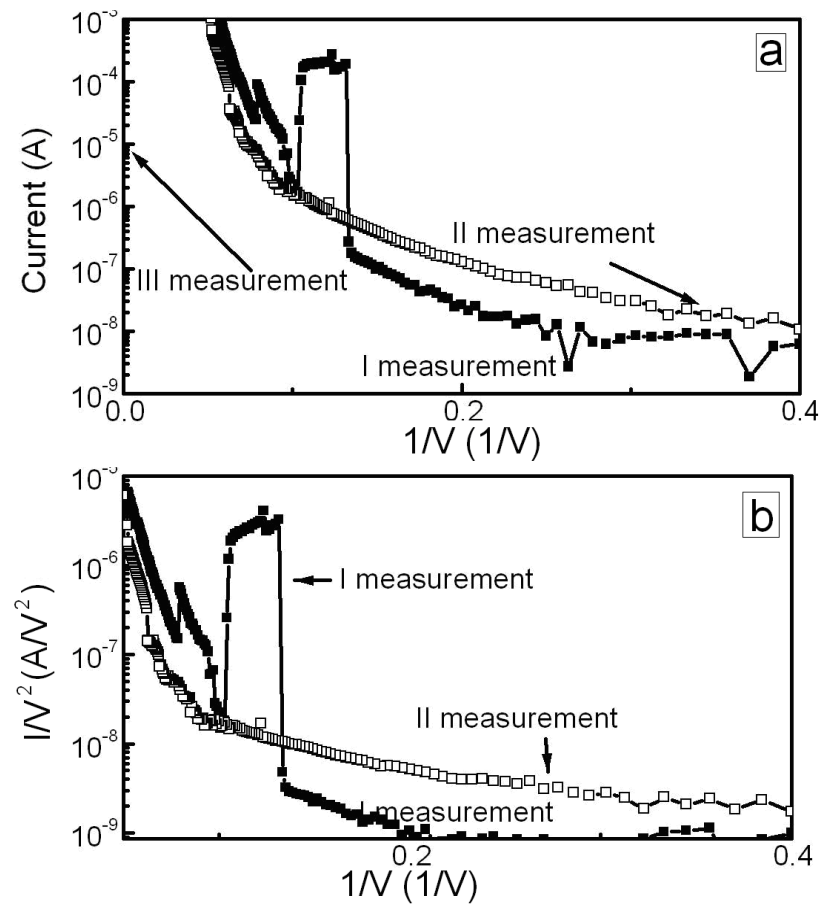

Fig. 8. Trap activated tunneling plot (a) and Fowler-Nordheim plot (b) of the DLC: $\mathrm{SiO}_{\mathrm{x}} / \mathrm{DLC} / \mathrm{DLC}: \mathrm{SiO}_{\mathrm{x}}$ superlattice fabricated on p-type silicon: III type I-V characteristics heterojunction and $\mathrm{DLC}: \mathrm{SiO}_{\mathrm{x}} / \mathrm{DLC} / \mathrm{DLC}: \mathrm{SiO}_{\mathrm{x}} / n \mathrm{Si}$ structures some kind of the current steps were detected for most samples investigated. It was explained by different charge transfer mechanisms - Schottky emission in low voltage range and superposition of the space charge limited current and generation current at higher voltages. However, it seems, that electric current flow through the diamond like carbon superlattice results in formation of some additional defects. Such an effect was not observed for a single $\mathrm{DLC}: \mathrm{SiO}_{\mathrm{x}} / n \mathrm{Si}$ heterostructure. Therefore, formation of the traps as a result of the damage of the "conventional" DLC interlayer in diamond like carbon superlattice can be assumed. In the case of the forward I-V characteristics for some samples negative resistance effect was observed. However, in most cases these I-V characteristics were unstable. It seems, that the negative resistance phenomenon was more often observed in the case of the samples with thicker intermediate DLC interlayer ( $\geq 4 \mathrm{~nm})$. In the case of the samples with negative resistance range in $\mathrm{I}-\mathrm{V}$ characteristics, current induced damages resulted in both disappearance of the negative resistance phenomena and contact limited charge transport mechanisms in the samples. While for the samples with no negative resistance phenomena observed, current induced damage resulted in flow of the mixed contact and bulk limited current at lower voltages instead of the contact limited current. In the case of the DLC: $\mathrm{SiO}_{\mathrm{x}} / \mathrm{DLC} / \mathrm{DLC}: \mathrm{SiO}_{\mathrm{x}}$ superlattices fabricated on p-type silicon symmetric or quasi-symmetric I-V characteristics were observed. For the most samples electric current induced changes of the I-V characteristics decrease of the turn-on voltage or even transition to the ohmic conductivity. For some DLC: $\mathrm{SiO}_{x} / \mathrm{DLC}_{\mathrm{DLC}}: \mathrm{SiO}_{\mathrm{x}}$ superlattices fabricated on p-type silicon negative resistance effect was observed). That effect was more pronounced than in the case of the samples fabricated on $n$-Si. In the case of the DLC: $\mathrm{SiO}_{\mathrm{x}} / \mathrm{DLC} / \mathrm{DLC}: \mathrm{SiO}_{\mathrm{x}}$ superlattices fabricated on p-type silicon for some samples negative resistance effect remained after the first measurement. Fowler-Nordheim and trap activated tunneling appeared to be the main charge transfer mechanisms in DLC: $\mathrm{SiO}_{\mathrm{x}} / \mathrm{DLC} / \mathrm{DLC}: \mathrm{SiO}_{\mathrm{x}} / p \mathrm{Si}$ samples. Current flow related disappearance of the negative resistance effect possibly can be explained by electrically induced damage of the DLC interlayer. Such a behavior can be explained taking into account case of the negative differential resistance in organic semiconductor based structures and devices [16-18]. Negative differential resistance effect was observed in numerous organic semiconductor based structures [16-18]. It was explained by strongly inhomogeneous current flow through the filamentary microconducting channels and subsequent decrease of the current due to the strong local heating by current flowing via strongly localized pathways [16-18]. Similarly negative differential resistance effect observed for PLD deposited DLC superlattice in [8,9] was explained by current flow through the $\mathrm{sp}^{2}$-rich one-dimensional channels within $\mathrm{sp}^{3}$ bonded carbon matrix. It should be mentioned, that in the case of the organic semiconductors negative resistance phenomena was more stable in comparison with the diamond like carbon superlattices described in present study. Thus negative resistance phenomena observed in 
present research for some DLC superlattices possibly can be explained by current flow through the $\mathrm{sp}^{2}$-rich microconducting channels within mainly $\mathrm{sp}^{3}$ bonded carbon matrix and local heating that microfilaments by flowing electric current. It seems, that in the case of the diamond like carbon superlattices investigated in present research local heating in local microconducting channels in most cases resulted in irreversible destruction of that localized current pathways. It can be mentioned, that no instability of $\mathrm{I}-\mathrm{V}$ characteristics was reported for DLC based tunnel diodes in $[8,9]$. However, negative resistance peak for PLD deposited DLC superlattice was observed only at $77 \mathrm{~K}$ temperature [8]. Negative resistance phenomena were observed at room temperature for nitrogen doped DLC based structure in [9]. However, in that case tunneling via potential barrier at DLC/silicon heterostructure was responsible for the phenomena observed [9].

\section{CONCLUSIONS}

In conclusion in present research current-voltage characteristics and charge transfer mechanisms of diamond like carbon based superlattices deposited on n-type and p-type monocrystalline silicon substrates were investigated. Diode-like I-V characteristics were observed for DLC superlattices fabricated on $n \mathrm{Si}$, while for DLC superlattices fabricated on p-type silicon symmetric or quasisymmetric I-V characteristics were observed. In the case of the forward I-V characteristics for some samples fabricated on $n \mathrm{Si}$ negative resistance effect was observed. For some DLC superlattices fabricated on $p \mathrm{Si}$ negative resistance effect was observed as well. The negative resistance phenomenon was more often observed in the case of the samples with thicker intermediate DLC interlayer $(\geq 4 \mathrm{~nm})$. However, in most cases that phenomenon was unstable, especially in the case of the samples deposited on $n \mathrm{Si}$. Presence of negative resistance phenomena in some DLC superlattices possibly can be explained by current flow through the $\mathrm{sp}^{2}$-rich microconducting channels within mainly $\mathrm{sp}^{3}$ bonded carbon matrix and local heating that microfilaments by flowing electric current. Local heating in local microconducting channels in most cases results in irreversible destruction of that localized current pathways.

\section{Acknowledgements}

Andrius Vasiliauskas would like to thank for grant in the frames of the project "Promotion of Students' Scientific Activities". Šarūnas Meškinis would like to acknowledge Lithuanian Ministry of Education and Science for the State grant of the researcher.

\section{REFERENCES}

1. Robertson, J. Diamond-like Amorphous Carbon Materials Science and Engineering R 37 2002: pp. 129-281.

2. Barthelmes, R., Beuermann, M., Metzner, D., Schmidt, G., Westerholt, D., Winter, N., Gerstenmaier, Y. C., Reznik, D., Ruff, M., $\quad$ Schulze, H.-J. Electroactive Passivation of High Power Semiconductor Devices with Punch through Design by Hydrogenated Amorphous Carbon Layers (a-C:H) Proceedings of 1998 International Symposium on Power Semiconductor Devices \& ICs 1998: pp. $181-184$.
3. Luo, J. K., Fu, Y. Q., Le, H. R., Williams, J. A., Spearing, S. M., Milne, W. I. Diamond and Diamond-like Carbon MEMS Journal of Micromechanics and Microengineering 17 2007: pp. S147-S163.

4. Tibrewala, A., Peiner, E., Bandorf, R., Biehl, S., Luthje, H. Longitudinal and Transversal Piezoresistive Effect in Hydrogenated Amorphous Carbon Films Thin Solid Films 515 2007: pp. 8028-8033.

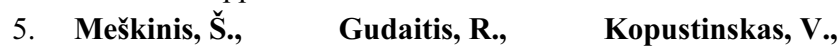
Tamulevičius, S. Electrical and Piezoresistive Properties of Ion Beam Deposited DLC Films Applied Surface Science 254 2008: pp. $5252-5256$.

6. Meškinis, $\breve{\text { S} ., ~} \quad$ Gudaitis, R., $\quad$ Tamulevičienè, A., Kopustinskas, V., Šlapikas, K., Tamulevičius, S. The Investigation of Piezoresistive, Optical and Electrical Properties of Diamond Like Carbon Films Synthesized by Ion Beam Deposition and PECVD Materials Science (Medžiagotyra) $16 \quad$ 2010: 292-297.

7. Chiang, K. T., Yang, L., Wei, R., Coulter, K. Development of Diamond-like Carbon-coated Electrodes for Corrosion Sensor Applications at High Temperatures Thin Solid Films 517 2008: pp. 1120-1124.

8. Bhattacharyya, S., Henley, S. J., Mendoza, E., GomezRojas, L., Allam, J., Silva, S. R. P. Resonant Tunnelling and Fast Switching in Amorphous-carbon Quantum-well Structures Nature Materials 5 2006: pp. 19-22.

9. Bhattacharyya, S., Silva, S., Ravi, P. Demonstration of an Amorphous Carbon Tunnel Diode Applied Physics Letters 90 2007: 082105.

10. Meškinis, Š., Šlapikas, K., Gudaitis, R., Tamulevičius, S., Iljinas, A., Gudonytė, A., Gražulevičius, J. V., Getautis, V., Michalevičiūtè, A., Malinauskas, T., Lygaitis, R. Investigation of the Electrical Characteristics of the Metal / Organic Semiconductor / Metal Structures with Top Contact Configuration Materials Science (Medžiagotyra) 16 2010: pp. 195-201.

11. Gonon, P., Deneuville, A., Fontaine, F., Gheeraert, E. Electrical Conduction and Deep Levels in Polycrystalline Diamond Films Journal of Applied Physics 78 1995: pp. $6633-6638$.

12. Houng, M. P., Wang, Y. H., Chang, W. J. Current Transport Mechanism in Trapped Oxides: a Generalized Trap-assisted Tunneling Model Journal of Applied Physics 86 1999: pp. 1488 - 1491.

13. Anatoly, A., Grinberg, Luryi, S., Pito, M. R., Schryer, N. L. Space-charge-Limited Current in a Film IEEE Transactions on Electron Devices $36 \quad$ 1989: pp. $1162-1170$.

14. Taylor, D. M. Space Charges and Traps in Polymer Electronics IEEE Transactions on Dielectrics and Electrical Insulation 13 2006: pp. 1063 -1073.

15. Miranda, E., Suñé, J., Rodríguez, R., Nafría, M., Aymerich, X. Breakdown and Anti-breakdown Events in High-field Stressed Ultrathin Gate Oxides Solid-State Electronics 45 2001: pp. 1327-1332.

16. Lebedev, E., Forero, S., Brütting, W., Schwoerer, M. Switching Effect in Poly(p-phenylenevinylene) Synthetic Metals 111-112 2000: pp. 345-347.

17. You, Y. T., Wang, M. L., Xuxie, H. N., Wu, B., Sun, Z. Y., Hou, X. Y. Conductance-dependent Negative Differential Resistance in Organic Memory Devices Applied Physics Letters 97 2010: 233301.

18. Berleb, S., Batting, W., Schwoerer, M. Anomalous Current-voltage Characteristics in Organic Light-emitting Devices Synthetic Metals 102 1999: 1034-1037. 